\title{
Analisis User Interface terhadap Website Berbasis E-Learning dengan Metode Heuristic Evaluation
}

\author{
Yemima Monica Geasela ${ }^{1}$, Pranchis Ranting ${ }^{2}$, Johanes Fernandes Andry ${ }^{3}$ \\ ${ }^{1}$ Universitas Bunda Mulia \\ e-mail: yemimageasela28@gmail.com \\ ${ }^{2}$ Universitas Bunda Mulia \\ e-mail: pranchisranting@gmail.com \\ ${ }^{3}$ Universitas Bunda Mulia \\ e-mail: jf_andry@kreavindo.com
}

\begin{abstract}
Abstrak
Dengan berkembangnya teknologi informasi, meningkat pula cara pembelajaran yang semakin modern salah satunya dengan menggunakan e-learning. E-learning adalah suatu model pembelajaran yang menggunakan website sebagai media dasarnya. Dengan adanya elearning, pembelajaran dapat dilakukan dimanapun dan kapanpun. E-learning yang baik adalah e-learning yang dapat meningkatkan kemampuan pengguna yang menggunakannya. Desain antarmuka menjadi salah satu elemen paling penting yang dapat mendukung kualitas edukasi di dunia maya. Oleh karena itu, penelitian ini bertujuan mengevaluasi desain antarmuka suatu website berbasis e-learning menggunakan human factors dan pendekatan interpretasi ergonomik, untuk meningkatkan usability dan usefulness sebuah sistem. Metode yang dipakai dalam penelitian ini adalah evaluasi heuristik yang terdiri atas 10 aturan prinsipnya yang terkenal dalam melakukan penilaian atas suatu desain antarmuka. Hasil penelitian menunjukkan secara umum penilaian terhadap desain interface dan ketermudahan penggunaan suatu website yang memiliki basis e-learning ditemukan telah cukup baik, akan tetapi masih terdapat beberapa hal yang perlu ditingkatkan, terutama yang bersesuaian dengan karakteristik dalam ketermudahan penggunaan.
\end{abstract}

Kata Kunci: website, e-learning, heuristic, usability

\begin{abstract}
With the development of information technology, studying process is one of the affected aspect by technology and becoming a new modern studying method called e-learning. E-Learning is a studying model that use website as it basis. With the help of e-learning, studying process can be done anywhere and anytime. A good E-Learning is one that can increase the overall skill of the user. Visual design becoming one of the support element that can help the education quality in cyberspace. Therefore, this research purposes aims is to design an e-learning website using human factor and ergonomi interpretation approaches, to improve the usefulness for user and the usefulness for system. The method used in this research is a method that consist of ten rule that was famous for designing. The result of general research about user interface design and the content about e-learning with a basis of website was good enough, but there is still some problem that must be fixed especially those relating with user experience.
\end{abstract}

Keywords: website, e-learning, heuristic, usability

\section{Pendahuluan}

Perkembangan ilmu pengetahuan yang meningkat begitu cepat tentunya diiringi dengan kemajuan teknologi yang berkembang pesat dan menuntun manusia ke era informasi (Deny, \& Andry, 2017).
Teknologi informasi yang berkembang saat ini sangat memudahkan para pemakainya untuk dapat melakukan komunikasi dengan praktis dalam berbagai tujuan yang diinginkan dan telah banyak dimanfaatkan oleh berbagai organisasi (Setiawan, \& 
Mustofa, 2013). Kemajuan pesat dalam bidang teknologi sangat membantu kegiatan manusia sehari-hari termasuk dalam kegiatan pembelajaran. Hal yang bisa dilihat sekarang ini adalah proses pembelajaran online dan salah satu aplikasi untuk melakukan pembelajaran online ini adalah dengan menggunakan website elearning.

Website adalah sebuah cara untuk menampilkan diri di Internet. Dapat diibaratkan website adalah sebuah tempat di Internet, siapa saja di dunia ini dapat mengunjunginya, kapan saja seseorang dapat mengetahui tentang diri orang lain, memberi pertanyaan pada seseorang, serta memberikan masukkan atau bahkan mengetahui dan membeli suatu produk (Nugraheny, 2016). Website memiliki berbagai jenis dan e-learning merupakan salah satu jenis dari website.

E-learning didefinisikan sebagai penyampaian materi dan metode pendidikan yang menggunakan teknologi informasi untuk keperluan pembelajaran, pengajaran, pelatihan atau memperoleh pengetahuan kapan pun dan di mana pun (Deny, \& Andry, 2017). Pemanfaatan elearning pada sebuah instansi pendidikan sangat dibutuhkan untuk membantu guru dalam meningkatkan proses pembelajaran. Seperti telah diketahui, pembelajaran di sekolah kejuruan mempunyai waktu pembelajaran praktik yang lebih banyak dibandingkan dengan pembelajaran teori atau pembelajaran di dalam kelas.

Dengan memanfaatkan e-learning sebagai media pembelajaran, dapat difungsikan sebagai pelengkap (komplemen) maupun suplemen untuk meningkatkan pembelajaran di dalam kelas sehingga dapat membantu meningkatkan pemahaman siswa terhadap materi dan meningkatkan kegiatan pembelajaran di sekolah kejuruan (Hanum, 2013). Sehingga dalam kehidupan manusia sekarang, media ini merupakan salah satu perkembangan teknologi yang sangat berguna bagi kehidupan manusia terutama dalam peningkatan dibidang ilmu pengetahuan atau edukasi. Salah satu komponen penting yang dapat meningkatkan ketergunaan website berbasis e-learning adalah segi tampilan antar muka atau yang biasa disebut dengan user interface.

Yang menghubungkan user dengan website atau teknologi disebut dengan user interface. User interface ini sendiri memiliki desain yang berbeda-beda berdasarkan fungsi dan kebutuhannya (Nurlifa, Kusumadewi, \& Kariyam, 2014). Terkadang dalam suatu website berbasis e-learning tidak bergitu memperhatikan desain antarmuka sehingga membuat para penggunakan tidak mendapatkan rasa nyaman dan mudah dalam menggunakan website tersebut dan hal ini yang membuat desain antarmuka menjadi salah satu hal yang penting bagi website berbasis $e$ learning. Dengan terciptanya user interface yang baik akan mendorong semangat belajar bagi pengguna website berbasis $e$ learning sehingga menciptakan kenyamanan dan kemudahan yang diharapkan.

Kenyamanan dan kemudahan (usability) memiliki subjenis salah satunya adalah Human Computer Interaction $(\mathrm{HCl})$. $\mathrm{HCl}$ sendiri merupakan interaksi yang terjadi antara komputer dan pengguna yang berfokus pada desain, evaluasi serta implementasi dari interaksi tersebut (Caesaron, 2015). Untuk melakukan analisis terhadap desain antarmuka $\mathrm{HCl}$ tersebut dapat menggunakan salah satu metode analisis yaitu Heuristic Evaluation.

Berdasarkan hal tersebut, pada penelitian ini kami akan melakukan sebuah analisa terhadap user interface dari suatu website e-learning menggunakan metode evaluasi heuristik (heauristic evaluation).

\section{Metode Penelitian}

Dalam penelitian ini, terdapat beberapa tahapan penelitian. Tahapan penelitian yang dipaparkan ini berguna untuk memberikan sebuah gambaran tentang keseluruhan pelaksanaan penelitian yang dilakukan dari awal pelaksaan penelitian hingga akhir dari tahap pelaksaan penelitian ini. Tahapan tersebut dapat dilihat pada gambar 1 :

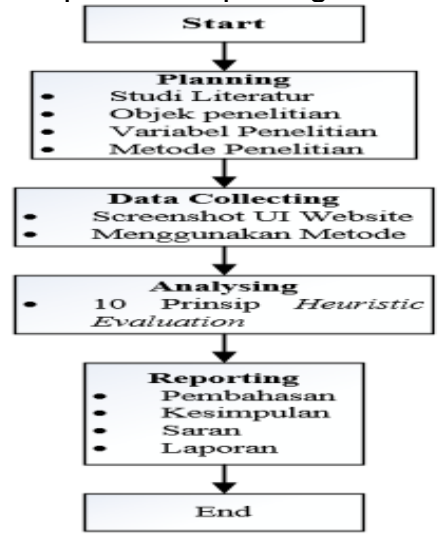

Gambar 1. Tahapan Penelitian 
Berdasarkan gambar 1 di atas, diketahui bahwa penelitian ini dimulai dari planning atau perencanaan melalui studi literatur, mencari objek yang akan diteliti, menentukan variabel penelitian, lalu menentukan metode yang akan digunakan sesuai dengan objek dan variabel tersebut.

Kemudian, masuk kedalam tahap data collecting atau pengambilan tampilan dari website yang akan dianalisis lalu menganalisis tampilan website tersebut. Analisis tampilan website tersebut akan dilakukan dengan 10 prinsip yang ada pada metode heuristic evaluation versi Molich dan Nielsen.

Heusristic evaluation itu sendiri merupakan panduan, prinsip umum, atau aturan yang dapat menuntun keputusan rancangan atau digunakan untuk mengkritik suatu keputusan yang sudah diambil. Evaluasi Heuristik diusulkan oleh Nielsen dan Molich, hampir sama dengan Cognitive Walkthrough tetapi sedikit terstruktur dan sedikit terarah. Pada pendekatan ini, sekumpulan kriteria usability atau heuristic diidentifikasi dan perancangan dilaksanakan misalnya dimana kriteria dilanggar (Savitri, \& Ispani, 2015).

Tujuan dari evaluasi heuristik adalah untuk memperbaiki perancangan secara efektif. Evaluator melakukan evaluasi melalui kinerja dari serangkaian tugas dengan perancangan dan dilihat kesesuaiannya dengan kriteria setiap tingkat. Jika ada kesalahan terdeteksi maka perancangan dapat ditinjau ulang untuk memperbaiki masalah ini sebelum tingkat implementasi (Savitri, \& Ispani, 2015).

Evaluasi Heuristik sangat baik digunakan sebagai teknik evaluasi desain, karena lebih mudah untuk menemukan atau menentukan masalah usability yang muncul. Untuk menggunakan evaluasi ini dibutuhkan software yang akan diteliti atau storyboard untuk sistem yang akan dibuat (Savitri, \& Ispani, 2015).

Setelah analisis terhadap objek sesuai dengan prinsip metode yang digunakan telah selesai dilakukan, maka tahap selanjutnya dibuat laporan mengenai pembahasan atas hasil analisis yang telah didapat serta kesimpulan dan saran dari analisis tersebut.

Pada tabel 1 akan menjelaskan mengenai 10 prinsip metode heuristic evaluation yang digunakan beserta keterangan-keterangan mengenai setiap prinsip-prinsip dari heuristic evaluation.
Tabel 1. Skala Penilaian

\begin{tabular}{|c|c|}
\hline Prinsip & Keterangan \\
\hline $\begin{array}{l}\text { Visibility of } \\
\text { system status } \\
\text { (feedback) }\end{array}$ & $\begin{array}{c}\text { Terdapat informasi } \\
\text { terhapat status sitem } \\
\text { saat ini dalam bentuk } \\
\text { pesan dan waktu yang } \\
\text { sesuai }\end{array}$ \\
\hline $\begin{array}{l}\text { Match between } \\
\text { system and the } \\
\text { real world }\end{array}$ & $\begin{array}{l}\text { Bahasa sistem sesuai } \\
\text { dengan bahas yang } \\
\text { digunakan pengguna }\end{array}$ \\
\hline $\begin{array}{l}\text { Use Control and } \\
\text { Freedom }\end{array}$ & $\begin{array}{l}\text { Pengguna mempunyai } \\
\text { kendali dan kebebasan } \\
\text { dalam mengambil suatu } \\
\text { keputusan }\end{array}$ \\
\hline $\begin{array}{l}\text { Consistency } \\
\text { and Standards }\end{array}$ & $\begin{array}{l}\text { Standar yang digunakan } \\
\text { sistem harus konsisten }\end{array}$ \\
\hline $\begin{array}{l}\text { Error } \\
\text { Prevention }\end{array}$ & $\begin{array}{l}\text { Terdapat sistem yang } \\
\text { mencegah terjadinya } \\
\text { kesalah }\end{array}$ \\
\hline $\begin{array}{l}\text { Recognation } \\
\text { Rather than } \\
\text { Recall }\end{array}$ & $\begin{array}{c}\text { Membantu pengguna } \\
\text { dalam mengenali, men- } \\
\text { diagnosa, dan } \\
\text { mengatasi masalah }\end{array}$ \\
\hline $\begin{array}{l}\text { Flexibility and } \\
\text { Efficient of Use }\end{array}$ & $\begin{array}{c}\text { Sistem dapat } \\
\text { mengakomodasikan } \\
\text { pengguna yang ahli dan } \\
\text { pengguna pemula }\end{array}$ \\
\hline $\begin{array}{l}\text { Aesthetic and } \\
\text { Minimalist } \\
\text { Design }\end{array}$ & $\begin{array}{c}\text { Memberikan informais } \\
\text { yang relevan serta } \\
\text { tampilan yang sesuai } \\
\text { dengan kebutuhan } \\
\text { sistem } \\
\end{array}$ \\
\hline $\begin{array}{l}\text { Help users } \\
\text { recognize, } \\
\text { dialogue, and } \\
\text { recovers from } \\
\text { errors }\end{array}$ & $\begin{array}{c}\text { Memberikan bantual } \\
\text { bagi pengguna dalam } \\
\text { mengenal, berdialog, } \\
\text { serta memperbaiki } \\
\text { kesalahan }\end{array}$ \\
\hline $\begin{array}{l}\text { Help and } \\
\text { Documentation }\end{array}$ & $\begin{array}{c}\text { Sistem memliki } \\
\text { dokumentasi yang } \\
\text { relevan serta fitur help } \\
\text { yang baik }\end{array}$ \\
\hline
\end{tabular}

Sumber: Savitri, \& Ispani (2015)

Jenis penelitian ini adalah penelitian deskriptif kualitatif, yaitu suatu metode penelitian yang dilakukan dengan tujuan utama untuk membuat gambaran atau deskripsi keadaan.

Pada penelitian ini, variabelvariavel yang akan digunakan untuk mendukung penelitian ini adalah:

a) Variabel bebas: desain tampilan antarmuka (user interface) website.

b) Variabel terikat: usability website.

c) Variabel kontrol: 10 dasar prinsip pada metode heuristic evaluation. 
Pengumpulan data berdasarkan cara perolehannya termasuk kedalam data primer, dikarenakan peneliti langsung meneliti dari objek penelitiannya yaitu website user interface.

Berikut adalah proses yang dilakukan dalam melakukan pengumpulan data:

a). Melakukan pengamatan terhadap user interface pada masing-masing bagian website-nya

b). Melakukan screen capture tampilan form dari website yang diteliti.

c). Dan seterusnya.

\section{Hasil dan Pembahasan}

Berikut adalah hasil analisis yang dilaksanakan oleh para peneliti mengenai penilaian terhadap masing-masing tampilan desain user interface pada website Net Acad yang berdasarkan penilaian menurut prinsip-prinsip yang terdapat pada metode evaluasi heuristik.

\subsection{Visibility of System Status (Feedback)}

I'm Learning

\section{Browse Course Catalog}

Courses I've Enrolled In

Gambar 2. Circle Running Progress

Sumber : https://www.netacad.com

Gambar 2 menunjukkan tampilan feedback pada website NetAcad yang menggunakan circle running progress bar pada saat sistem sedang melakukan pengambilan data atau loading.

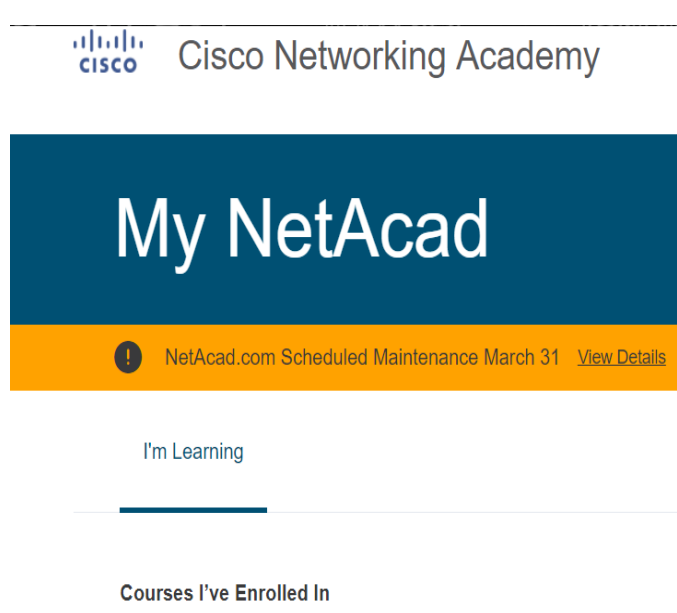

Gambar 3. Pemberitahuan Maintenance Sumber : https://www.netacad.com

Gambar 3 di atas memperlihatkan adanya pesan pemberitahuan atas kondisi dari sistem yang disampaikan oleh website NetAcad terhadap pengguna yang memakai website tersebut.

Berdasarkan dari gambar 2 dan 3 dapat diambil kesimpulan bahwa website NetAcad telah memenuhi prinsip pertama dari teori evaluasi heuristik, meskipun masih membutuhkan beberapa peningkatannya dan perbaikannya.

\subsection{Match Between System and the Real} World

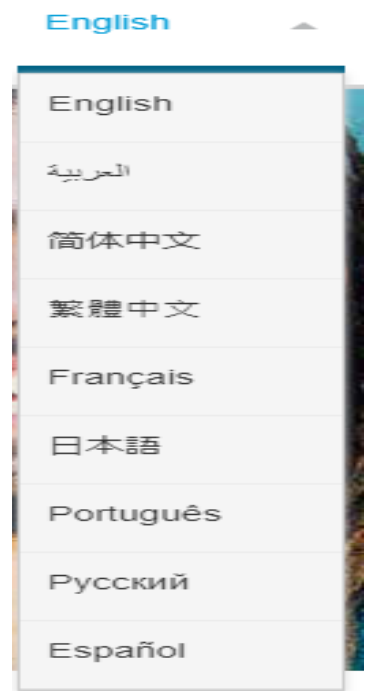

Gambar 4. Evaluasi metaphor Sumber : https://www.netacad.com 


\begin{abstract}
Gambar 4 menunjukkan bahwa website NetAcad telah menyediakan beberapa jenis bahasa yang paling sering digunakan oleh para pemakainya. Tetapi, akan jauh lebih baik agar website tersebut menambah jumlah bahasa yang dapat digunakan pada website tersebut, agar lebih banyak pemakainya yang akan merasa mudah menggunakan website ini.
\end{abstract}

\subsection{User Control and Freedom}
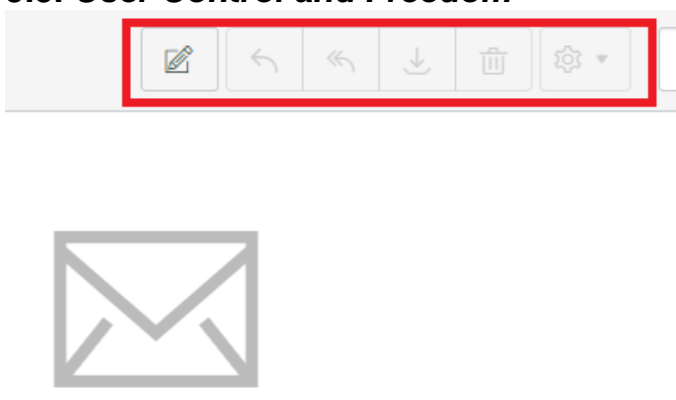

\section{Gambar 5. User Control and Freedom} Sumber : https://www.netacad.com

Pada gambar 5 di atas, dapat diketahui adanya tanda redo, delete, serta tanda lainnya yang berada pada form conversations. Dengan adanya tombol ini, maka pengguna akan merasa lebih mudah untuk mengoperasikan kegiatannya, apakah akan menghapus, mengulang, dan sebagainya. Dengan demikian, website ini dinilai telah memenuhi prinsip ke-3 dari evaluasi heuristik.

\subsection{Consistency and Standards}

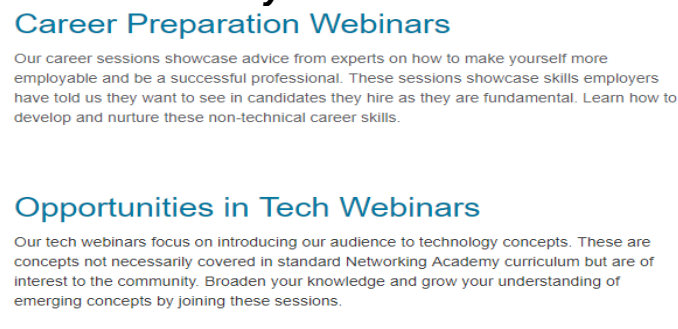

Gambar 6. Consistency and Sandards 1 Sumber : https://www.netacad.com

\section{Access Talent Bridge Matching Engine}

Search for jobs using our new Talent Bridge Matching Engine. Fill out your profile to search opportunity matches with Cisco as well as Cisco partners and distributors seeking Cisco Networking Academy students and alumni.

The Matching Engine is a new pilot program. Help us test its value by utilizing the tool and please be patient as we are in the process of adding new jobs from employers seeking
NetAcads, so check back frequently for job matches in your region.

Gambar 7. Consistency and Sandards 2 Sumber : https://www.netacad.com
Pada gambar 6 dan 7 dapat dilihat bahwa kedua tampilan yang terdapat pada website NetAcad tersebut telah menggunakan bahasa yang konsisten yaitu bahasa Inggris, serta menggunakan style font yang sama dan tidak berbeda-beda, meskipun font color-nya masih terdapat perbedaan. Walau begitu, website ini dinilai sudah cukup memenuhi prinsip ke-4 dari teori ini.

\subsection{Error Prevention}

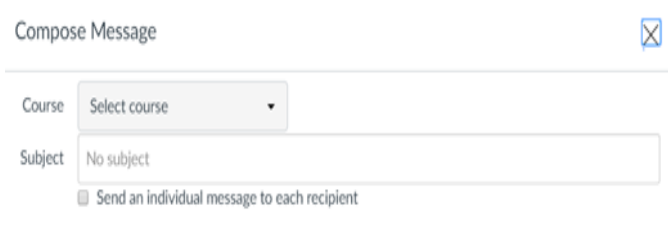

Gambar 8. Error Prevention

Sumber : https://www.netacad.com

Pada gambar 8 di atas, dapat dilihat bahwa pada website Net Acad terdapat adanya tanda " $X$ " pada bagian pojok kanan atas tampilan, dan beberapa menu yang ditampilkan seperti send, choose file dan lainnya. Hal ini berguna dalam membantu user untuk mencegah melakukan kesalahan. Adanya tanda dan tombol seperti itu, maka website ini sudah cukup memenuhi prinsip ke-5. akan tetapi, masih diperlukan peningkatan dan tambahan lain yang mungkin dapat diberikan seperti adanya spelling checker dan sebagainya.

\subsection{Recognation Rather Than Recall Search: CCNA}

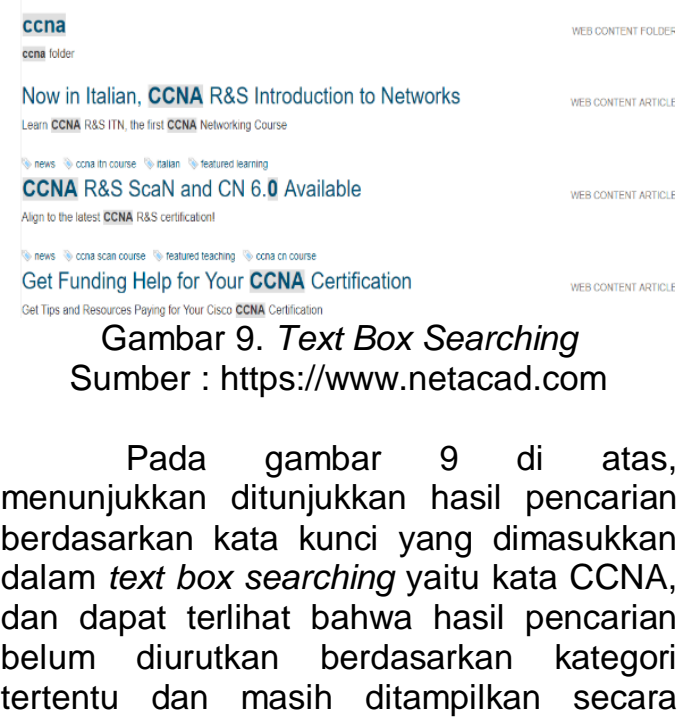


acak. Harap diketahui bahwa beban kerja akan meningkat saat pengguna perlu mencari informasi CCNA mana yang sebenarnya dituju atau dicari oleh pengguna. Maka diharapkan website NetAcad dapat memberikan kategori atau filter searching yang jauh lebih detail lagi sehingga mengurangi beban kerja dari penggunanya. Filter searching yang digunakan dapat diurutkan berdasarkan alfabetnya, waktu, favorit, dan kategori lainnya.

\subsection{Flexibility and Efficient Of Use}

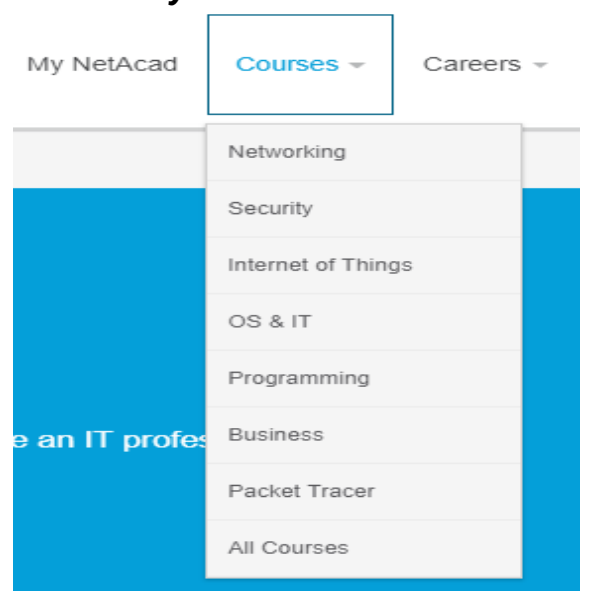

Gambar 10. Flexibility and Efficient Of Use Sumber : https://www.netacad.com

Pada gambar 10 di atas, dapat dilihat bahwa website Net Acad telah memberikan akomodasi dan penyediaan layanan yang berbeda-beda tergantung dari tingkat keahlian penggunanya. Pengguna juga dapat memilih sendiri sejauh mana pengguna akan mengambil atau mengikuti proses pembelajaran dari suatu materi.

\subsection{Aesthetic and Minimalist Design}

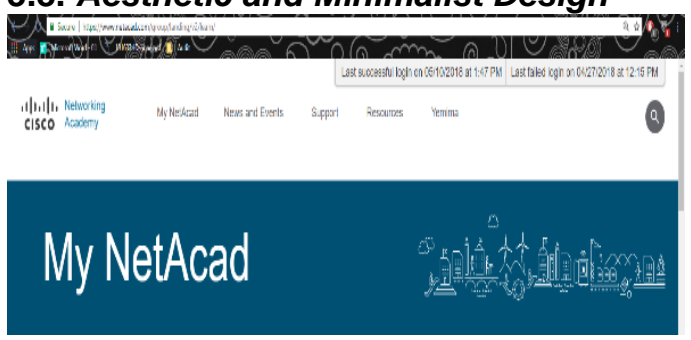

Gambar 11. Aesthetic and Minimalist Design

Sumber : https://www.netacad.com

Pada gambar 9 di atas, dapat dilihat bahwa informasi yang disampaikan sudah cukup relevan dengan tujuan pembangunan website, yaitu sebagai website e-learning. Desain user interface yang dimiliki oleh website ini pun telah terlihat cukup baik dan praktis untuk dipakai. Meski begitu, akan jauh lebih baik apabila website ini menyediakan pilihan warna bagi para user yang memakainya, seperti adanya pemilihan tema warna website pada setting, karena dengan begitu pengguna akan jauh lebih nyaman lagi pada saat menggunakan website tersebut.

\subsection{Help Users Recognize, Dialogue, and Recovers From Errors}

Cisco Networking Academy Log In

Authentication failed. Please try again

Email address or screen name

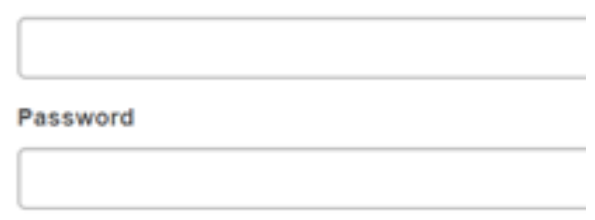

\section{$\log \ln$}

Gambar 12. Alert Warning Saat Login Sumber : https://www.netacad.com

Pada gambar 12 di atas, dapat dilihat bahwa website Net Acad tersebut telah memberikan peringatan jika terjadi kesalahan dalam proses validasi login, akan tetapi peringatan tersebut belum memberikan penjelasan yang cukup jelas terhadap sesuatu hal yang salah.

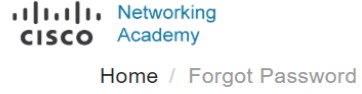

Forgot Password

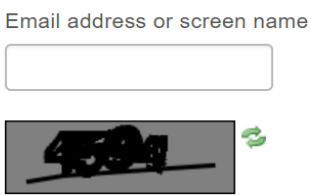

Text Verification

Send New Password

Gambar 12. Alert Warning Saat Login

Sumber : https://www.netacad.com

Pada gambar 13, dapat dilihat bahwa terdapat bantuan yang disediakan 
oleh website Net Acad untuk pengguna yang lupa terhadap password dari account user yang ada yaitu dengan disediakannya form forgot password. Dalam form tersebut, pengguna diminta untuk memasukkan alamat email pengguna serta text verification yang telah disediakan, setelah mengisi dengan tepat maka pengguna akan dapat melakukan pergantian password lewat link yang dikirimkan website ke email pengguna..

\subsection{Help and Documentation}

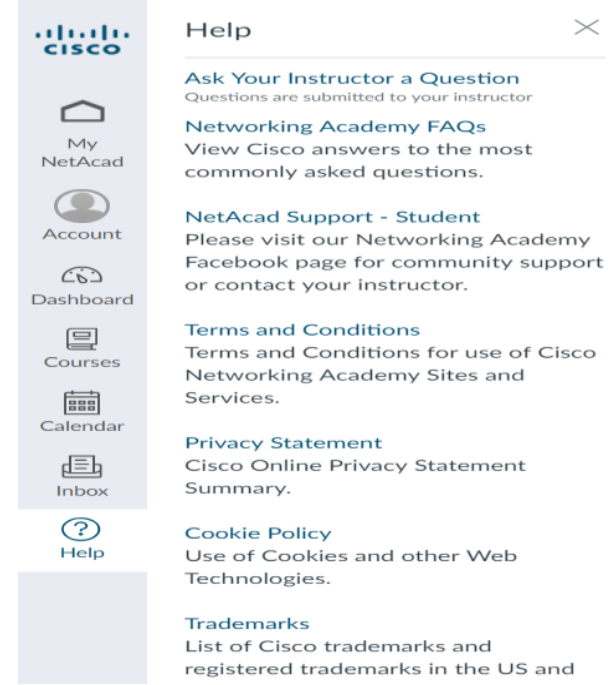

Gambar 14. Help and Documentation (1) Sumber : https://www.netacad.com System Help

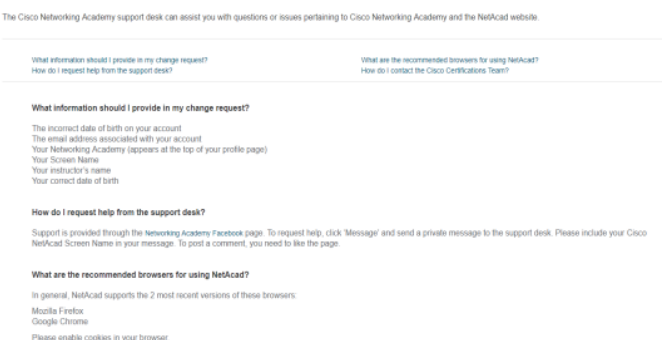

Gambar 15. Help and Documentation (2) Sumber : https://www.netacad.com

Pada gambar 14 dan gambar $15 \mathrm{di}$ atas, dapat dilihat beberapa bantuan yang telah disediakan oleh website Net Acad pada saat ini dan yang telah didokumentasikan pula. Menu help yang telah disediakan ini sudah cukup lengkap dan baik, akan tetapi jauh lebih baik apabila terdapat layanan help yang dilakukan secara online chat, sehingga pengguna dapat jauh lebih mudah dalam mengatasi kesulitan yang ditemukannya.

\section{Kesimpulan}

Berdasarkan dari hasil analisis penelitian yang telah dijelaskan sebelumnya, maka dapat ditarik kesimpulan bahwa website e-learning NetAcad memiliki desain user interface yang sudah cukup baik. Dikarenakan, desain dari website tersebut hampir memenuhi secara keseluruhan 10 prinsip yang dimiliki oleh teori evaluasi heuristik tersebut.

Website NetAcad memiliki tampilan yang menarik, praktis, serta menyediakan berbagai fasilitas dan layanan yang memang memudahkan penggunanya dalam menjalankan website tersebut.

Meski begitu, website ini masih memiliki beberapa kekurangan yang harus diperbaiki dan ditingkatkan, seperti menambah jenis bahasa yang dapat digunakan oleh pengguna, memberikan penjelasan lebih jauh atas kesalahan yang dilakukan pengguna saat memvalidasi akunnya saat hendak login, dan lain sebagainya.

\section{Referensi}

Caesaron, D. (2015). Evaluasi Heuristic Desain Antar Muka (Interface) Portal Mahasiswa (Studi Kasus Portal Mahasiswa Universitas X). Jurnal Metris, 16(1), 9-14.

Deni, \& Andry, J. F. (2018). Pengukuran Keberhasilan E-Learning dengan Mengadopsi Model Delone \& Mclean (in press). JSINBIS (Jurnal Sistem Informasi Bisnis), 8(1).

Hanum, N. (2013). Keefektifan E-Learning sebagai Media Pembelajaran (Studi Evaluasi Model Pembelajaran ELearning SMK Telkom Sandhy Putra Purwokerto). Jurnal Pendidikan Vokasi, 3(1).

Nugraheny, D. (2016). Analisis User Interface dan User Experience pada Website Sekolah Tinggi Teknologi Adisutjipto Yogyakarta. SENATIK, 2.

Nurlifa, A., Kusumadewi, S., \& Kariyam. (2014). Analisis Pengaruh User Interface terhadap Kemudahan Penggunaan Sistem Pendukung Keputusan Seorang Dokter. In Prosiding SNATIF (pp. 333-340). 
Savitri, P., \& Ispani, M. (2015). Review Desain Interface Aplikasi Sopppos Menggunakan Evaluasi Heuristik. Simetris: Jurnal Teknik Mesin, Elektro Dan IImu Komputer, 6(1), 95-100.

Setiawan, H., \& Mustofa, K. (2013). Metode Audit Tata Kelola Teknologi Informasi di Instansi Pemerintah Indonesia. Jurnal IPTEK-KOM, 15(1), 1-15. 